GRADIATION\&APPLICATIONS

ISSN 2466-4294 (online) | rad-journal.org

Vol. 3 | Issue 1 | pp. 34-40, 2018

doi: 10.21175/RadJ.2018.01.007

Original research paper

\title{
REMOTE CONTROL ROBOT FOR DECOMMISSIONING HORIZONTAL FUEL CHANNELS OF NUCLEAR REACTOR*
}

\author{
Constantin Popescu', Gabi Rosca-Fartat ${ }^{1 * *}$, Nicolae Pana1, Daniela Fluerasu ${ }^{2}$ \\ ${ }^{1}$ Polytechnic University, Bucharest, Romania \\ ${ }^{2}$ IFIN-HH, Bucharest, Romania
}

\begin{abstract}
The authors' contribution to this paper is to present a possible designing solution concept of the remote control robot for the decommissioning of the nuclear reactor horizontal fuel channels. In this paper, the authors present several properties of geometry, kinematics and dynamics of the robot movement into the reactor fuel channel and a few considerations required due to material thickness, according to the radiation protection procedures. The main stages of the dismantling operation in terms of operational safety are: positioning, coupling and locking, operating accordingly with the approved decommissioning procedures, sorting and storing the extracted items in the robot container. All operating steps are designed to be automated and performed by one robot which shall provide radiation protection during the dismantling stages, thus ensuring radiation protection of the workers. The operations are monitored by internal sensors and transducers, by pyrometer for temperature during the cutting process and video surveillance cameras for the dismantling components, in order to ensure assembly of operating facilities and a permanent control. The remote control robot radiation protection has a safety system able to extract the robot from the channel in case of a disruption of the blocking or decommissioning activities due to any error registered, in order to ensure the environmental and workers' protection.
\end{abstract}

Key words: Fuel channel, decommissioning, dismantling operation, radiation protection, remote control robot

\section{INTRODUCTION}

Decommissioning of fuel channels represents one of the last operations which are performed in the process of decommissioning the nuclear power plant and it is considered the most important in dismantling the nuclear reactor structure. Due to safety reasons, special devices with command and control from the outside (in remote control mode) should be used. The designed device shall provide a full protection of workers and environment against nuclear radiation during the decommissioning process.

\subsection{Dose estimation}

Assuming the total activity of long-lived isotopes of the pressure tubes from the nuclear reactor immediately after reactor shutdown, and the total activity on the decommissioning date (30 years after shutdown), the estimated dose is presented in Table 1 [20].

Table 1. Estimation of the dose received by the workers

\begin{tabular}{|c|c|c|c|c|c|}
\hline Radioisotope & $\begin{array}{c}\text { Co-6o } \\
\text { (Half life: } 5.27 y \text { ) }\end{array}$ & $\begin{array}{c}\text { Zr-95 } \\
\text { (Half life: } 64.02 d)\end{array}$ & $\begin{array}{c}\text { Nb-95 } \\
\text { (Half life: } 34 \cdot 975 \mathrm{~d} \text { ) }\end{array}$ & $\begin{array}{c}\text { Nb-94 } \\
\text { (Half life: } 20,300 y \text { ) }\end{array}$ & $\begin{array}{c}\text { Fe-55 } \\
\text { (Half life: } 2.73 y)\end{array}$ \\
\hline $\begin{array}{l}\text { Activity immediately after reactor } \\
\text { shutdown (TBq) }\end{array}$ & 229 & 141,000 & 141,000 & 274 & 3,700 \\
\hline $\begin{array}{l}\text { Activity at the decommissioning date } \\
\text { (after } 30 \text { years) (TBq) }\end{array}$ & 4.433 & $4.24 \mathrm{E}-047$ & $6.95 \mathrm{E}-090$ & 273,719 & 1.82 \\
\hline $\begin{array}{l}\text { Dose rate at } 5 \mathrm{~m} \text { without shielding } \\
(\mathrm{mSv} / \mathrm{h})\end{array}$ & 53,584 & $3.48 \mathrm{E}-046$ & $2.76 \mathrm{E}-\mathrm{o} 89$ & $2,245,204$ & negligible \\
\hline $\begin{array}{l}\text { Dose received at } 5 \mathrm{~m} \text { in } 0.5 \mathrm{~h} \text { work } \\
\text { time if the shielding is } 10 \mathrm{~cm} \\
\text { equivalent lead (mSv) }\end{array}$ & 0.109 & negligible & negligible & 0.196 & negligible \\
\hline $\begin{array}{l}\text { Total dose received in } 0.5 \mathrm{~h} \text { work } \\
\text { time at } 5 \mathrm{~m} \text { distance with shielding }\end{array}$ & \multicolumn{5}{|c|}{$0.305 \mathrm{mSv}$} \\
\hline
\end{tabular}

\footnotetext{
* The paper was presented at the Fifth International Conference on Radiation and Applications in Various Fields of Research (RAD 2017), Budva, Montenegro, 2017.

*rosca_gabi@yahoo.com
} 


\section{GENERAL PRESENTATION OF THE DEVICE}

Hereunder, the authors proposed a constructive solution for a Remote Control Robot (RCR) designed in order to provide a full protection of personnel and the environment against the nuclear radiation during the decommissioning process of the horizontal fuel channels in the CANDU 6 nuclear reactor.

\subsection{General considerations}

The Remote Control Robot (RCR) is able to ensure full radiation protection of personnel and the environment during all decommissioning steps performed.

The Remote Control Robot (RCR) is prepared to work on the both sides of the reactor (front and back) for dismantling the reactor fuel channels one by one.

The Remote Control Robot (RCR) is operated by a complex platform equipped with the general power supply, command panel, electrical actuators and geared motors to allow movement on all axis.

The principal physical characteristics of the RCR:

- Length $=8.3 \mathrm{~m}$, approx.

- Width $=1.2 \mathrm{~m}$ approx.

- Height $=1.5 \mathrm{~m}$ approx.

The principal physical characteristics of the platform:

- Length $=16.9 \mathrm{~m}$, approx.

- Width $=7.1 \mathrm{~m}$ approx.

- Height $=11.7 \mathrm{~m}$ approx.

\subsection{Device assembly presentation}

The Remote Control Robot (RCR) and its platform (P) are fixed from the beginning of the decommissioning process on the floor of the reactor chamber in front (or back) of the calandria structure (see Fig. 1):

1 - Front side of calandria reactor structure

2 - RCR

3 - Platform

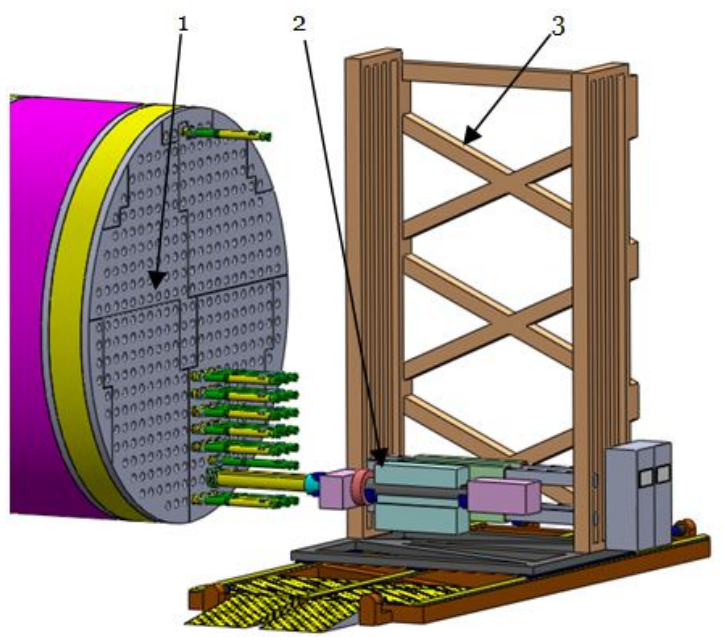

Figure 1. The Remote Control Robot on platform, in front of calandria structure

\subsubsection{Platform presentation}

The platform is a very rigid steel structure and has a base fixed on the floor of the calandria structure chamber. This base allows the access of the forklifts to retrieve the container at the end of operations for every fuel channel. For this reason, the base is equipped with an access ramp (see Fig. 2):

1 - Access ramp

2 - Fixed base

3 - Mobile base

4 - Vertical support structure

5 - Sled for moving horizontally and vertically

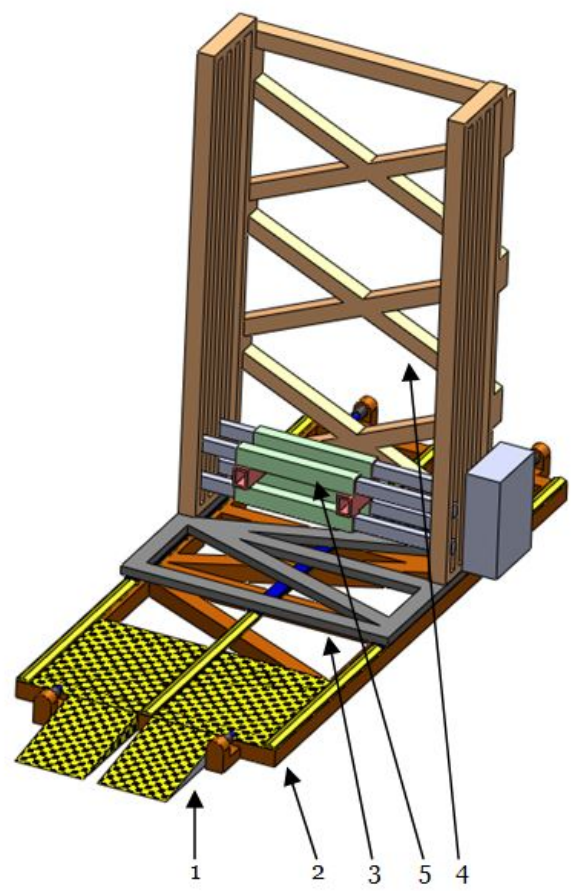

Figure 2. The platform

From the point of view of the degrees of freedom, the flexibility of the structure allows (see Fig.3):

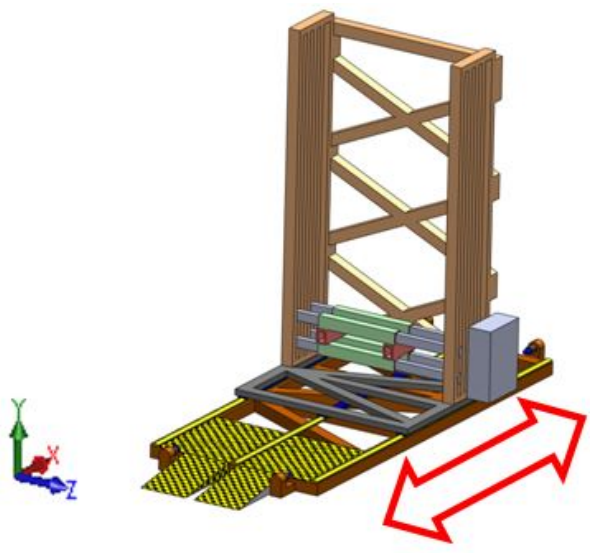

Figure 3. The platform - degrees of freedom 
1 - Access ramp - fixed on floor

2 - Fixed base - fixed on floor

3 - Mobile base - one translation along the $\mathrm{X}$ axis

4 - Vertical support structure - joined with mobile base

5 - Sled for moving horizontally and vertically three degrees of freedom, one on each axis (see Fig. 4)

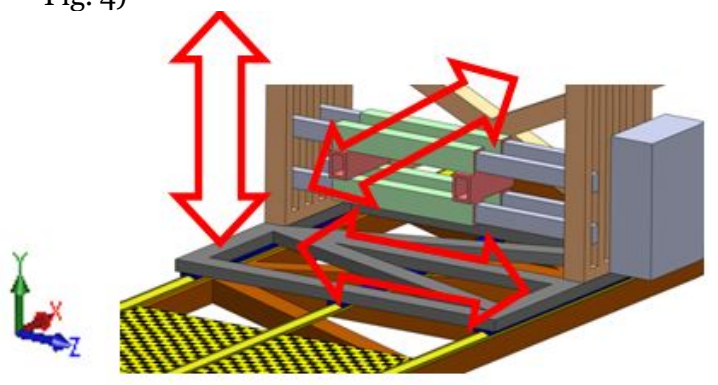

Figure 4. The mobile sled - degrees of freedom

The sliding of the mobile base along the $\mathrm{X}$ axis is defined as a quick motion and is available grace of the three sliders in $\mathrm{V}$ shape with rolls. On each side of the fixed base there are stopper actuators, provided to limit the movement of the mobile base (see Fig.5).

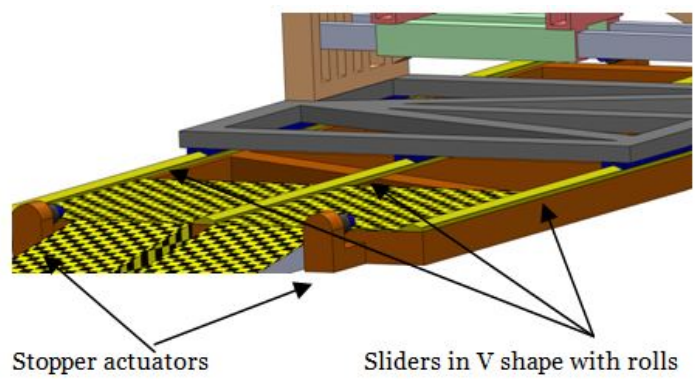

Figure 5. Stopper actuators and sliders on fixed base

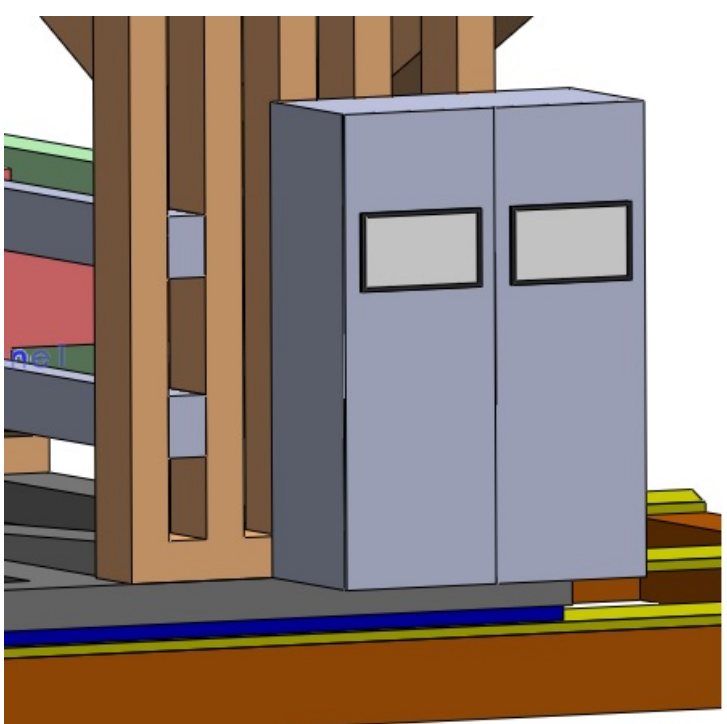

Figure 6. Command panel
In the structure of the platform, the command panel is also integrated which allows to fully control the RCR by a Programmable Logic Controller (PLC) and operate it with a Human Machine Interface (HMI) (see Fig. 6).

The platform is also controlled by the second PLC with HMI from the command panel.

\subsubsection{The Remote Control Robot (RCR) presentation}

The proposed solution design is a Remote Control Robot (RCR), which has a compact and flexible structure able to perform all operations in the decommissioning process as follows: extracting the channel closure plug and the channel shield plug, cutting the pressure tube (PT) in four parts during the extracting phase, extracting and cutting the end fitting (EF) in two parts when extracting it.

All operations performed achieve the maximum radiation protection degree and represent a safety solution to protect the operators and the environment.

The Remote Control Robot (RCR) is a closed system - all extracted components remain stored inside the safety container.

The main components of RCR are (see Fig. 7):

1 - safety bellows

2 - connecting pipe

3 - safety valve

4- tool chamber

5 - external cutting device

6 - rods chamber

7 - safety container

8 - motors chamber

9 - chassis

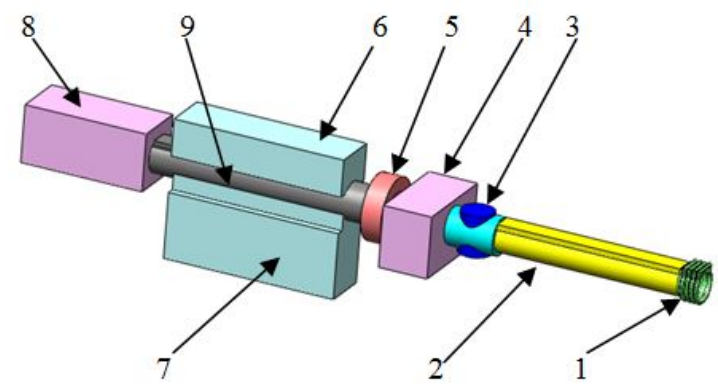

Figure 7. The Remote Control Robot (RCR)

From the point of view of the degrees of freedom, the structure of RCR allows (see Fig.8):

1 - safety bellows - one translation on $\mathrm{Z}$ axis and one rotation around the $\mathrm{Z}$ axis (the bellows is joined to the connecting pipe) (see Fig.8): 


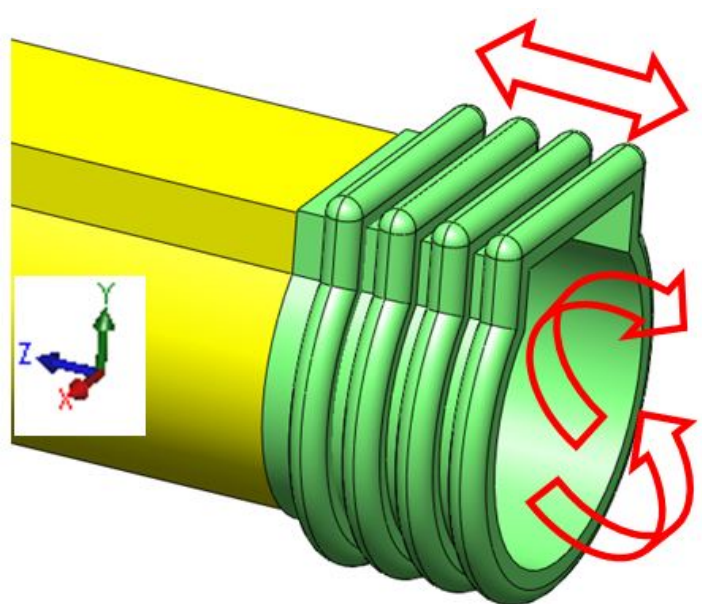

Figure 8 . The safety bellows - degrees of freedom

2 - connecting pipe - one rotation around the $\mathrm{Z}$ axis (needed to allow the connection with the end fittings which are not in vertical position) (see Fig. 9):

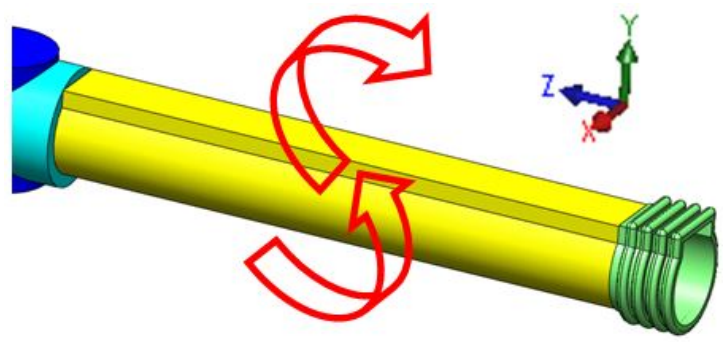

Figure 9. The connecting pipe - degrees of freedom

3 - safety valve - one rotation around the $\mathrm{Y}$ axis (needed to allow the closing of the fuel channel during some operations) (see Fig. 10):

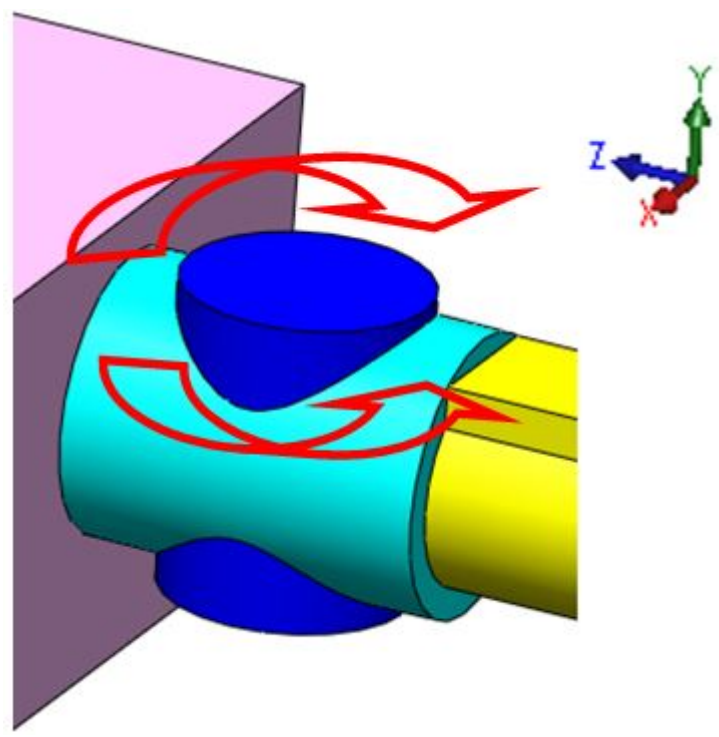

Figure 10. The safety valve - degrees of freedom
4 - tool chamber - the inside support for head tools stored inside this area has two translation options: on $\mathrm{X}$ and $\mathrm{Y}$ axis (see Fig. 11):

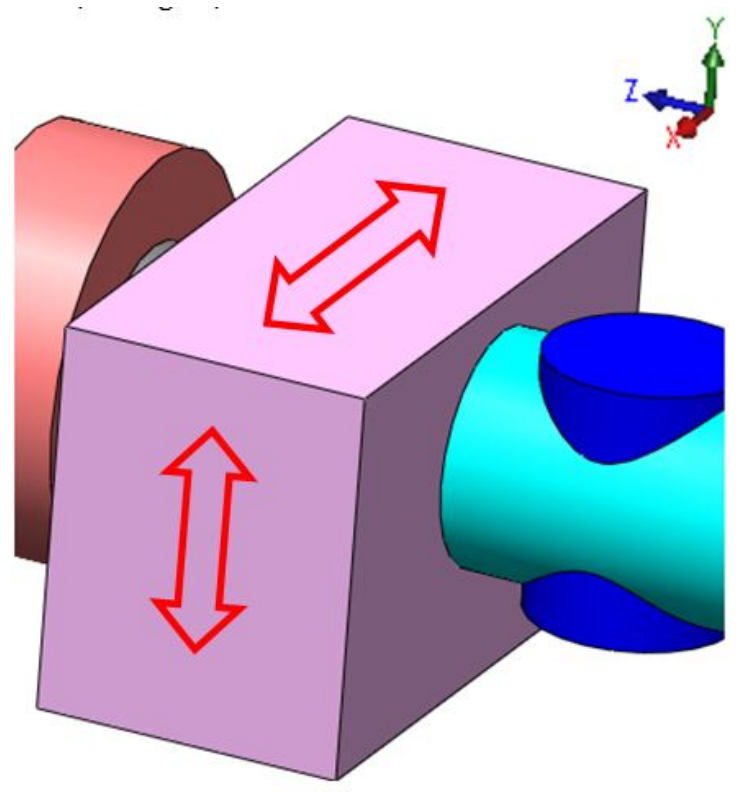

Figure 11. The tool chamber - degrees of freedom

5 - external cutting device - one rotation around the $\mathrm{Z}$ axis (needed to cut the extracted tubes) (see Fig. 12):

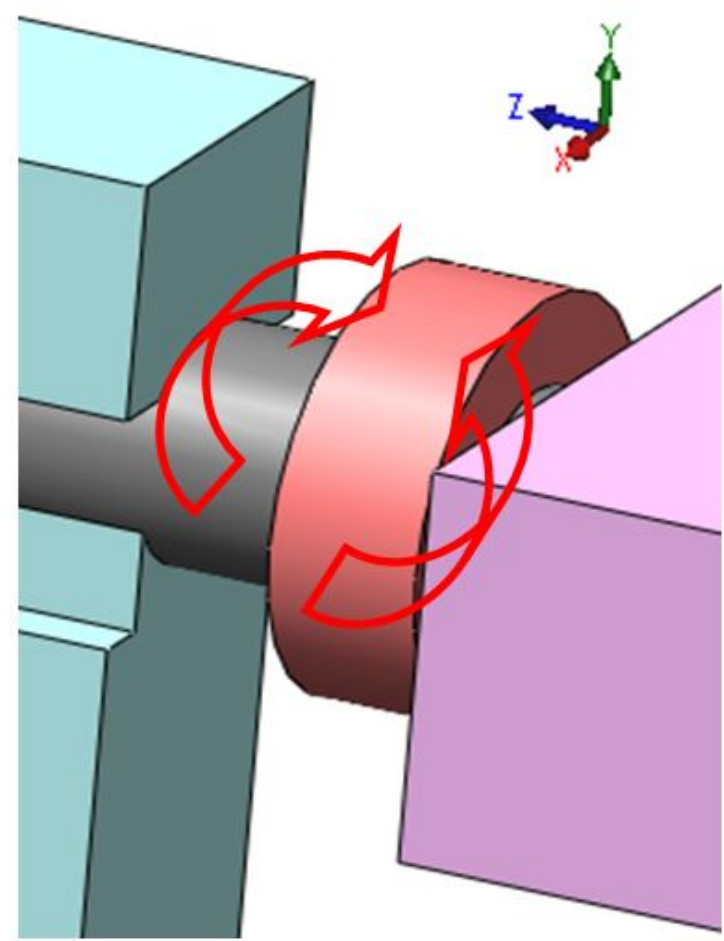

Figure 12. The external cutting device - degrees of freedom 
6 - rods chamber - the inside support of rod tools stored inside this area has one translation option on $\mathrm{Y}$ axis (see Fig. 13):

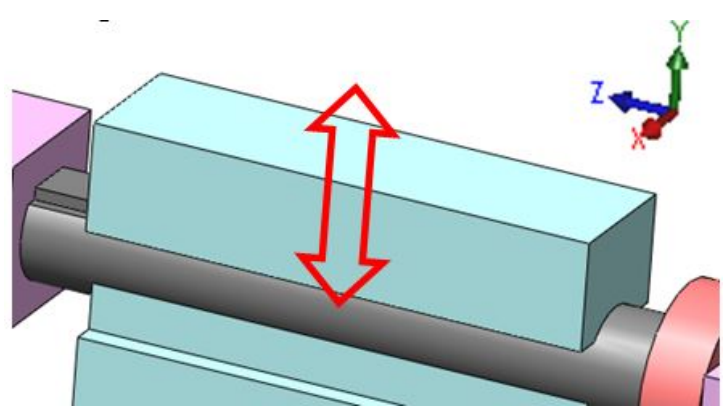

Figure 13. The rods chamber - degrees of freedom

7 - safety container - it is fixed on the chassis and could be removed from the RCR chassis when the operations are finished and have inside all the extracted components, stored in safety conditions (see Fig. 14):

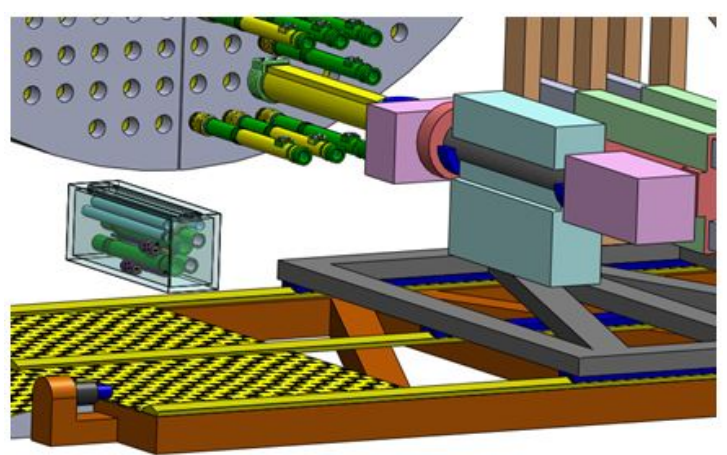

Figure 14. The safety container in removed position

8 - motors chamber - fixed on the chassis (see Fig. 15):

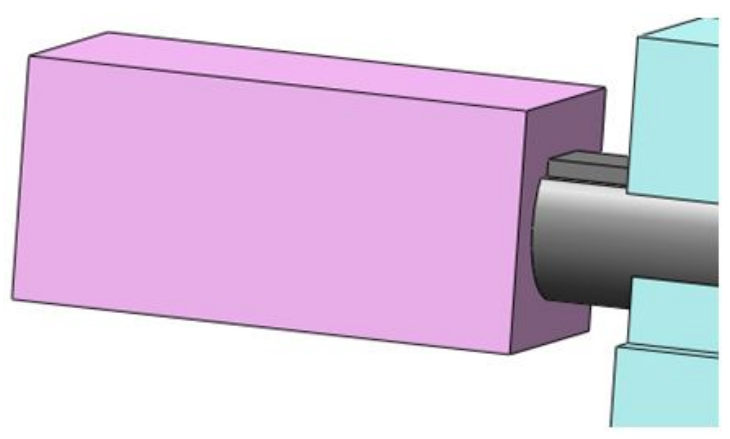

Figure 15. The motors chamber on the chassis
Fig. 16):

- chassis - fixed on the platform supports (see

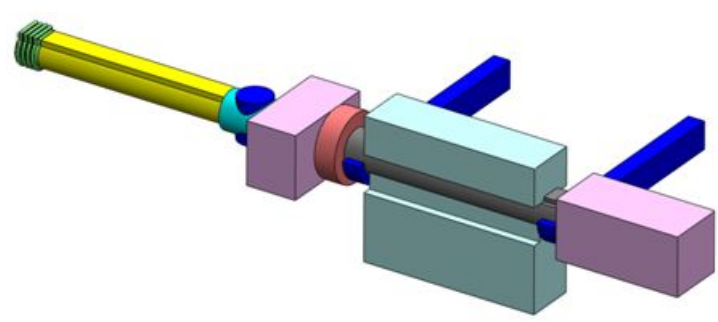

Figure 16. The chassis on the supports of platform

\subsubsection{The Remote Control Robot (RCR) material components}

From a radiation protection point of view, the thicknesses of all components are considered based on dose estimation from point 1.1, remaining fully defined when the measurements are finished on site.

Fig. 17 shows the structure of walls and Table 2 presents the estimated thickness layers [mm] for the walls of each component.

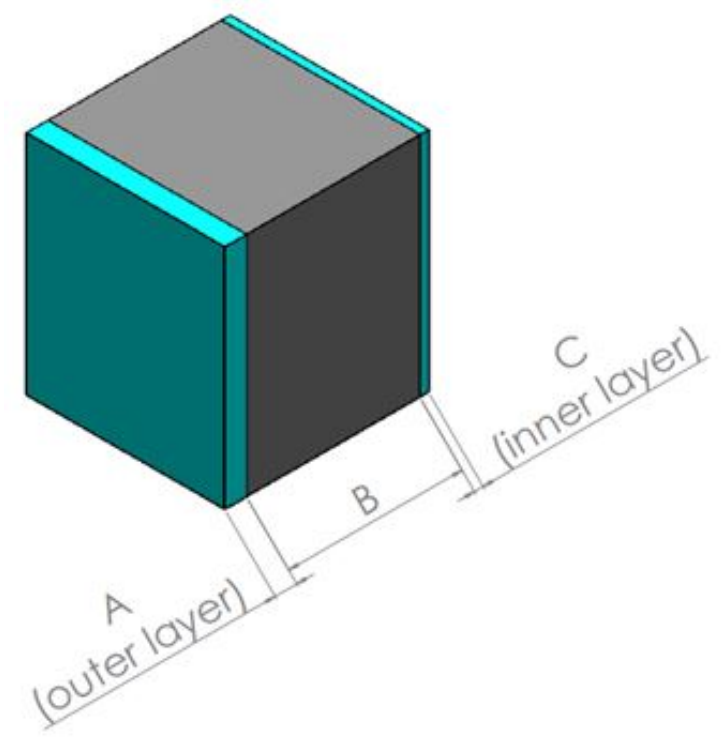

Figure 17. The wall structure 
C. Popescu et al., Remote control robot for decommissioning horizontal fuel channels.., Rad.Applic., 2018, 3, 1, 34-40

Table 2. Material and thickness layers

\begin{tabular}{|c|c|c|c|c|c|}
\hline \multirow[b]{2}{*}{ Pos. } & \multirow[b]{2}{*}{ Component } & \multicolumn{3}{|c|}{ Material \& Thickness layers [mm] } & \multirow[b]{2}{*}{ Comments } \\
\hline & & $\begin{array}{l}\text { A - Stainless } \\
\text { steel }\end{array}$ & B - Lead & $\begin{array}{l}\mathrm{C}-\text { Stainless } \\
\text { steel }\end{array}$ & \\
\hline 1 & Safety bellows & 20 & & & Extracted components pass quickly through this section \\
\hline 2 & Connecting pipe & 20 & & & Extracted components pass quickly through this section \\
\hline 3 & Safety valve & 30 & 60 & 10 & Critical part \\
\hline 4 & Tool chamber & 30 & 60 & 10 & Tools are contaminated during operations \\
\hline 5 & $\begin{array}{l}\text { External cutting } \\
\text { device }\end{array}$ & 30 & 80 & 10 & End fitting and Pressure tube are cut in this section \\
\hline 6 & Rods chamber & 30 & 80 & 10 & Rods are contaminated during operations \\
\hline 7 & Safety container & 30 & 100 & 30 & $\begin{array}{l}\text { Critical part } \\
\text { Extracted components are stored into a safety container }\end{array}$ \\
\hline 8 & Motors chamber & 20 & & & Not in direct contact with extracted components \\
\hline 9 & Chassis & 30 & & & Main pipe - contaminated during operations \\
\hline
\end{tabular}

\subsubsection{The Remote Control Robot (RCR) order of} operations in decommissioning process

In terms of radiation protection, the Remote Control Robot (RCR) is designed to perform all operations in decommissioning process on the both faces of calandria structure as follows:

a) On the back face:

- extracting the channel closure plug and storing it in the safety container;

- extracting the channel shield plug and storing it in the safety container;

- cutting the pressure tube (PT) at one end;

- extracting the end fitting of this side;

- cutting end fitting (EF) in two parts and storing them one by one in the safety container.

- closing the calandria pipe with a safety lid.

b) Move the platform on the front side of calandria structure and perform:

- extracting the channel closure plug and storing it in the safety container;

- extracting the channel shield plug and storing it in the safety container;

- cutting the pressure tube (PT) at one end;

- extracting the end fitting of this side;

- cutting end fitting (EF) in two parts and storing them one by one in the safety container;

- extracting the pressure tube (PT);

- during the extracting phase, PT is cut in four parts and they are stored in the safety container one by one;

- closing the calandria pipe with a safety lid.

\section{CONCLUSIONS}

The proposed design of the Remote Control Robot (RCR) could be continuously developed with respect to the AECL (Atomic Energy of Canada Limited) rules and other international standards to ensure the maximum safety against the nuclear radiation during exploitation life.

All components should be carefully checked according to the maintenance rules and any deviation needs corrective actions.

\section{REFERENCES}

1. Assessment and management of ageing of major nuclear power plant components important to safety: CANDU reactor assemblies, IAEA-TECDOC1197, IAEA, Vienna, Austria, 2001

Retrieved from: https://www-

pub.iaea.org/MTCD/publications/PDF/te_1197_prn .pdf;

Retrieved on: Jan. 10, 2018

2. Decommissioning of Nuclear Power Plants and Research Reactors, IAEA Safety Standard Series No. WS-G-2.1, IAEA, Vienna, Austria, 1999.

Retrieved from: https://wwwpub.iaea.org/MTCD/Publications/PDF/Po79 scr.pd

Retrieved on: Jan. 10, 2018

3. Atomic Energy of Canada Limited, AECL, Ottawa, Canada, 2014.

Retrieved from: http://www.aecl.ca/en/home/news/ news-archives/2014-10-10-launch-of-canadiannuclear-laboratories.aspx;

Retrieved on: Jan. 10, 2018

4. Nuclear Power Plant Design Characteristics, IAEATECDOC-1544, IAEA, Vienna, Austria, 2007.

Retrieved from: https://wwwpub.iaea.org/MTCD/Publications/PDF/te 1544 we b.pdf;

Retrieved on: Jan. 10, 2018

5. B. A. Cheadle, E. G. Price, "Operating performance of CANDU pressure tubes," presented at the IAEA Technical Committee Meeting on the Exchange of Operational Safety Experience of Heavy Water Reactors, Vienna, Austria, Feb. 1989

Retrieved from: http://www.iaea.org/inis/collection /NCLCollectionStore/ Public/23/059/23059653.pd

Retrieved on: Jan. 10, 2018

6. K. Heyde, Basic Ideas and Concepts in Nuclear Physics: an introductory approach, Bristol, UK: Institute of Physics Publishing, 1994.

Retrieved from: http://www.fisica.net/nuclear/basic ideas and concepts in nuclear physics an intr oductory approach.pdf;

Retrieved on: Jan. 10, 2018

7. R. G. Steed, Nuclear Power in Canada and Beyond, Renfrew, Canada: General Store Publishing House, 2007.

8. Fundamentals of power reactors, AECL, Ottawa, Canada, 1993.

Retrieved from: https://canteach.candu.org/Content \%20Library/Forms/AllItems.aspx; Retrieved on: Jan. 10, 2018

9. ANSTO Replacement Research Reactor Project: SAR Chapter 19 - Decommissioning, Rep. RRRP- 
C. Popescu et al., Remote control robot for decommissioning horizontal fuel channels.., Rad.Applic., 2018, 3, 1, 34-40

7225-EBEAN-002-REVo-CHAPTER-19, ANSTO, Sydney, Australia, 2004.

Retrieved from: https://www.arpansa.gov.au/sites/g /files/net3086/f/legacy/pubs/regulatory/opal/op/S AR/ch19.pdf;

Retrieved on: Jan. 10, 2018

10. Enhanced CANDU 6: Technical Summary, SNCLAVALIN, Montreal, Canada, 2015.

Retrieved from: http://www.snclavalin.com/en/files

/documents/publications/enhanced-candu-6-

technical-summary en.pdf;

Retrieved on: Jan. 10, 2018

11. National Commission for Nuclear Activities Control.

(Oct. 10, 1996). Law no. 111/1996 on the safe deployment, regulation, authorization and control of nuclear activities.

Retrieved from: http://www.cncan.ro/assets/Legisla tie/Law-no-111-of-19962006-final.doc;

Retrieved on: Jan. 10. 2018

12. Comisia Nationala pentru Controlul Activitatilor Nucleare. (15.9.2002). NSN-15 Normele de dezafectare a obiectivelor si instala tiilor nucleare. (National Commission for Nuclear Activities Control. (Sep. 9, 2002). NSN-15 Rules for the decommissioning of objectives and nuclear installations.)

Retrieved from: http://www.cncan.ro/assets/nsn/ns n15.pdf;

Retrieved on: Jan. 15, 2018

13. S. Venkatapathi, A. Mehmi, H. Wong, "Pressure tube to end fitting roll expanded joints in CANDU PHWRS," presented at the Int. Conf. on Expanded and Rolled Joint Technology, Toronto, Canada, Sep. 1993.

14. Assessment and management of ageing of major nuclear power plant components important to safety: CANDU reactor assemblies, IAEA-TEDOC1197, IAEA, Vienna, Austria, 2001.

Retrieved from: https://www-

pub.iaea.org/MTCD/publications/PDF/te_1197_prn .pdf;

Retrieved on: Jan. 10, 2018
15. Organization and Management for Decommissioning of Large Nuclear Facilities, IAEA Technical Reports Series No. 399, IAEA, Vienna, Austria, 2000.

Retrieved from: https://wwwpub.iaea.org/MTCD/Publications/PDF/TRS399 scr .pdf;

Retrieved on: Jan. 10, 2018

16. Selection of decommissioning strategies: Issues and factors, IAEA-TECDOC-1478, IAEA, Vienna, Austria, 2005.

Retrieved from: https://www-

pub.iaea.org/MTCD/publications/PDF/TE_1478 w eb.pdf;

Retrieved on: Jan. 11, 2018

17. State of the Art Technology for Decontamination and Dismantling of Nuclear Facilities, IAEA Technical Reports Series No. 395, IAEA, Vienna, Austria, 1999

Retrieved from: https://www-

pub.iaea.org/mtcd/publications/pdf/trs395_scr/d39 5 part1 scr.pdf;

Retrieved on: Jan. 11, 2018

18. Water channel reactor fuels and fuel channels: Design, performance, research and development, IAEA-TECDOC-997, IAEA, Vienna, Austria, 1996.

Retrieved from: https://www-

pub.iaea.org/MTCD/publications/PDF/te 997_prn. pdf;

Retrieved on: Jan. 11, 2018

19. Heavy Water Reactors: Status and Projected Development, IAEA Technical Reports Series No. 407, IAEA, Vienna, Austria, 2002. Retrieved from: https://wwwpub.iaea.org/MTCD/publications/PDF/TRS407 scr $\angle \mathrm{D} 407$ scr1.pdf;

Retrieved on: Jan. 15, 2018

20. Preliminary decommissioning plan for the Point Lepreau generating station, Rep. N29-1387-003, TLG Services, Inc. Bridgewater (CT), USA, 2010. 